\title{
METHOD FOR ESTIMATION OF ROAD WHEELS ROLLING RESISTANCE IN RUBBER TRACK SYSTEMS
}

\author{
J. Chołodowski ${ }^{*}$ P. Dudziński**
}

\begin{abstract}
The Department of Off-Road Machine and Vehicle Engineering (Wrocław University of Science and Technology) conducts intensive research aimed at developing computational models for estimation of internal motion resistance of off-road vehicles with rubber tracks and belts. Internal rolling resistance of road wheels (rollers), caused by their interaction with tracks, is a significant factor affecting overall internal resistance of a rubber track system. The authors presented and verified an original, analytical-empirical model for estimation of rolling resistance of double flange roller coupled with rubber track. Values of main parameters of the model are derived from results of experiments carried out by the authors. The model estimates rolling resistance coefficient as a function of roller vertical load and the angle between inner track surface and roller's axis of rotation. According to evaluation performed herein, the model is suitable for calculating expected rolling resistance coefficient of rollers for engineering design computations purpose.
\end{abstract}

Keywords: rolling resistance, model, track crawler design, double flange roller, rubber track

\section{Introduction}

So as to properly define actual power demand of a rubber tracked crawler, all components of external and internal motion resistance should be thoroughly estimated. Unfortunately, accuracy of known internal motion resistance models is usually insufficient to do so. Consequently, the Department of Off-Road Machine and Vehicle Engineering has undertaken intensive research aimed at developing more accurate computational models (Dudziński, Chołodowski, 2016 and Dudziński, Chołodowski, 2017).

Suspension systems enabling road wheels to oscillate in transverse vehicle plane are nowadays implemented in some heavy duty machines with rubber belts and double flange rollers (Camso, 2018, Roth, 2004 and Rosenboom, 2008). Suspension of this type allows to effectively transmit high traction forces, prevents the tread of the tracks from non-uniform wear and may improve energy efficiency of rubber track system (Dudziński et al. 2018). Nevertheless, most of tracked vehicles lack such suspension so as to maintain simple construction. If such vehicle negotiates uneven terrain, at least several rollers' flanges lose contact with track surface, which may lead to increase in rolling resistance of particular rollers (Dudziński et al. 2018). Engineers should take the highlighted phenomenon into account while estimating internal resistance of rubber tracked vehicles being under development.

The authors of the following paper formulated and verified an analytical-empirical model for estimation of rolling resistance coefficient of double flange roller rolling over rubber track as a function of roller vertical load. The model predicts the influence of roller-track contact pressure non-uniformity on rolling resistance coefficient value.

M.Sc. Eng. Jakub Chołodowski: Department of Off-Road Machine and Vehicle Engineering, Wrocław University of Science and Technology, ul. Łukasiewicza 7/9; 50-371, Wrocław; PL, jakub.cholodowski@pwr.edu.pl

** Prof. Dr. habil. Eng. Piotr A. Dudziński: Department of Off-Road Machine and Vehicle Engineering, Wrocław University of Science and Technology, ul. Łukasiewicza 7/9; 50-371, Wrocław; PL, piotr.dudzinski@pwr.edu.pl 
2. Analytical-empirical model - main assumptions

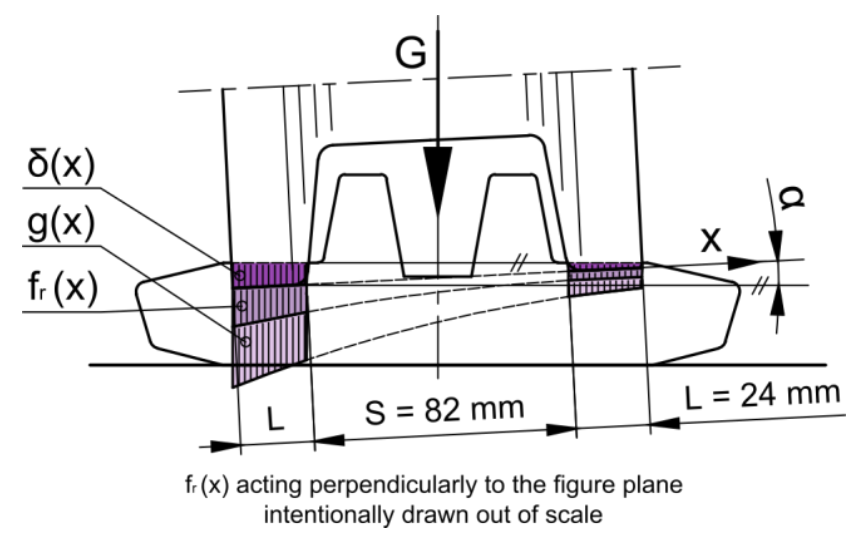

Fig. 1: Section of a roller and rubber track (with key parameters of proposed model highlighted)

According to proposed model, rolling resistance coefficient $f$ of double flange roller rolling over rubber track is a function of roller overall vertical load $G$ and the angle between inner track surface and roller's axis of rotation $\alpha$ (roller tilt angle). It is calculated basing on equations (1-6).

$$
\begin{gathered}
f=\frac{F_{R}}{G} \\
F_{R}=\int_{0}^{L} f_{r}(x) d x+\int_{S+L}^{S+2 L} f_{r}(x) d x \\
G=\int_{0}^{L} g(x) \cos \alpha d x+\int_{S+L}^{S+2 L} g(x) \cos \alpha d x \\
f_{r}(x)=a \cdot[g(x)]^{n} \\
g(x)=b \cdot[\delta(x)]^{m} \\
\delta(x)=\delta_{\text {min }}+x * \sin \alpha
\end{gathered}
$$

- $x-$ roller coordinate in roller lateral direction (see Fig. 1.),

- $S$ - distance between roller flanges,

- $L$ - width of a single roller flange,

- $\delta(x)$ - rubber track vertical deflection distribution considered in transverse roller/track plane,

- $f_{r}(x)$ - unit roller rolling resistance force (per unit width of roller),

- $g(x)$ - roller-track unit contact pressure distribution (per unit width of roller),

- $\quad a, b, n, m$ - model parameters depending on elasticity modulus and damping of rubber track material as well as roller geometry.

\section{Model verification}

Presented model was verified by comparison of experimental results discussed in (Dudziński et al., 2018) with results of rolling resistance coefficient computations performed by the model for roller considered in (Dudziński et al., 2018). Rolling resistance coefficient was calculated at two roller tilt angles $-\alpha_{1}=3^{\mathrm{O}}$, $\alpha_{2}=7^{\mathrm{O}}$ - and various roller vertical loads.

Based on geometrical dimensions of the roller, $L=24 \mathrm{~mm}$ and $S=82 \mathrm{~mm}$ (see Fig. 1.) were assumed.

Parameters $a$ and $n$, eq. (4), were derived from empirical relationship between rolling resistance force and vertical load of considered roller which was determined in (Dudziński, Chołodowski, 2017) in uniform roller-track contact pressure conditions. Firstly $n=1.35$ was assumed. Secondly parameter $a$ was evaluated on the basis of equations $(8,9)$.

$$
\begin{gathered}
F_{R}=0.0034 G^{1.35} \\
0.0034 G^{1.35}=\int_{0}^{L} a \cdot g(x)^{1.35} d x+\int_{S+L}^{S+2 L} a \cdot g(x)^{1.35} d x \\
g(x)=\frac{G}{2 L}
\end{gathered}
$$


Parameters $b$ and $m$, eq. (5), were derived from empirical relationship between vertical reaction force in roller-track contact and rubber track deflection given by equation (10) (see also Fig. 2.). The relationship was determined using the test stand presented in (Dudziński et al., 2018). Track deflection was measured using LVDT linear position transducer.

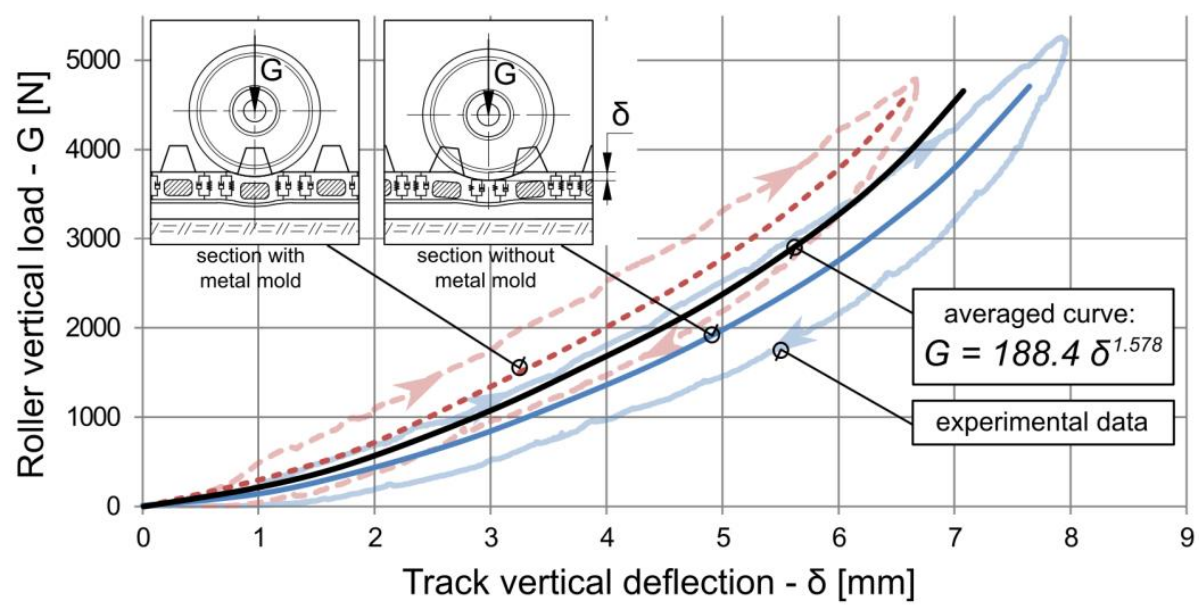

Fig. 2: Experimental contact stiffness characteristics of considered roller and rubber track

According to Fig. 2., roller-track contact stiffness characteristics depend on investigated track cross section. For this reason the averaged curve was involved in $b$ and $m$ parameters calculations. Eventually it was assumed that $m=1.578$, whereas parameter $b$ should fulfill equations $(11,12)$.

$$
\begin{gathered}
G=188.4 \delta^{1.578} \\
188.4 \delta^{1.578}=\int_{0}^{L} b \cdot \delta(x)^{1.578} d x+\int_{S+L}^{S+2 L} b \cdot \delta(x)^{1.578} d x \\
\delta(x)=\delta=\text { const }
\end{gathered}
$$

Figure 3. illustrates comparison of model computations results with actual values of rolling resistance coefficient determined experimentally.

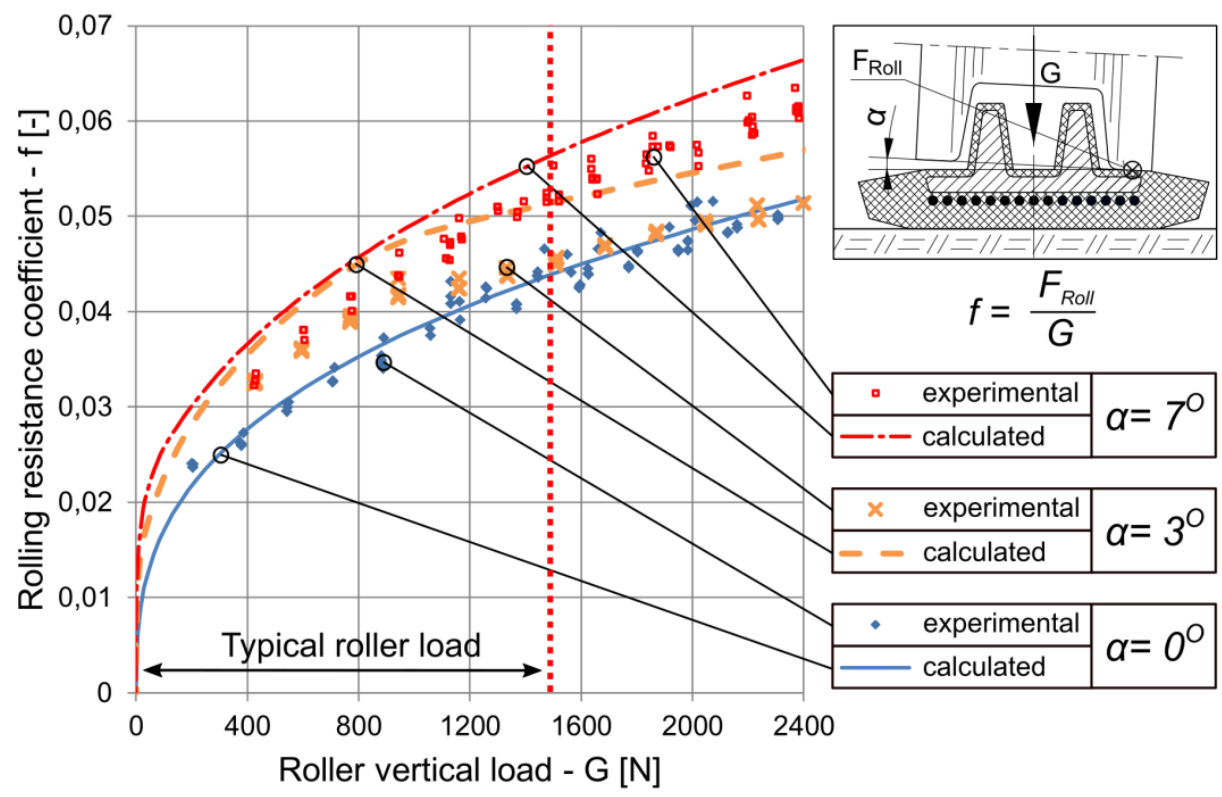

Fig. 3: Rolling resistance coefficient of exemplary double flange roller coupled with rubber track as a function of roller vertical load and roller tilt angle - experimental results obtained in (Dudziński, Chołodowski, 2018) compared with model prediction 


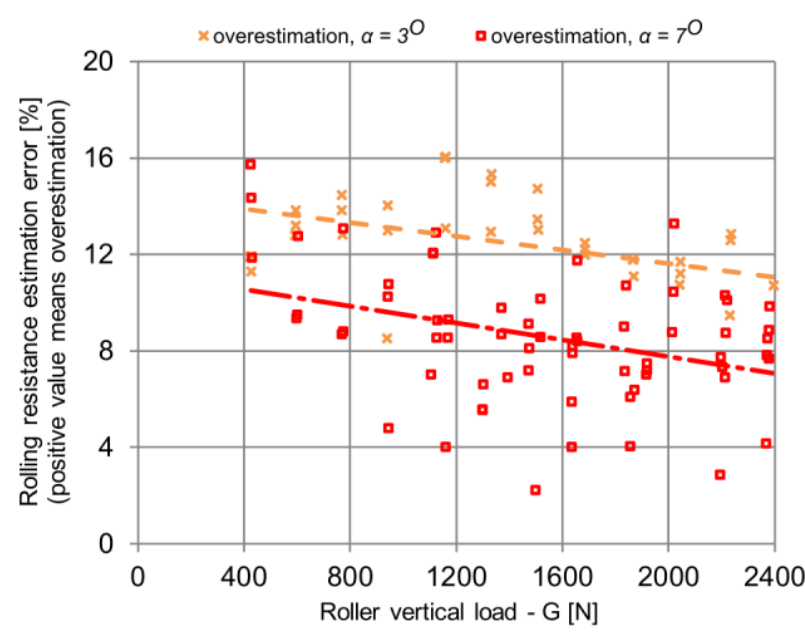

Fig. 4: Overestimation of rolling resistance coefficient by means of proposed computational model

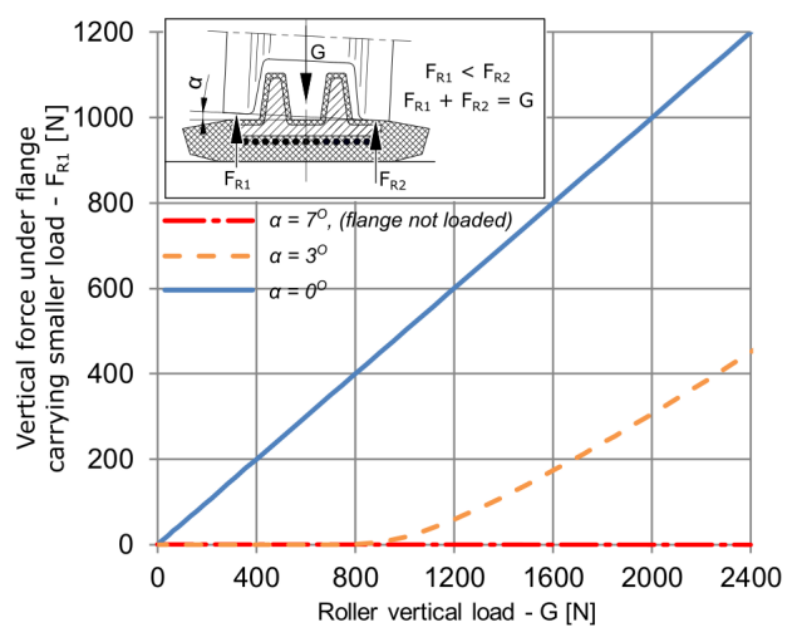

Fig. 5: Vertical reaction force acting on roller's flange carrying smaller load as a function of overall roller vertical load

In comparison with experimental results, the model overestimated rolling resistance coefficient by no more than $16 \%$ (Fig. 4.). Hence, rolling resistance force absolute estimation error was smaller than 10N. Which is notable, rolling resistance coefficient changes caused by no contact between one of roller's flanges and the track were successfully predicted by the model. Results of computations performed for roller tilt angle $\alpha_{2}=7^{\mathrm{O}}$ indicate that vertical load is carried by only one roller's flange at any considered load, which results in increase in rolling resistance in comparison with zero tilt angle conditions. On the other hand, according to calculations at tilt angle $\alpha_{1}=3^{\mathrm{O}}$, load is transferred to the track by single roller's flange until the load is smaller than $800 \mathrm{~N}$. In such conditions predicted rolling resistance coefficient values are similar to those calculated at $\alpha_{2}=7^{\circ}$. At higher loads the load is split between both flanges (Fig. 5.) which results in intermediate rolling resistance coefficient values.

\section{Conclusions}

The paper presents an analytical-empirical model that enables to estimate rolling resistance coefficient of double flange roller coupled with rubber track as a function of roller vertical load as well as the angle between inner track surface and roller's axis of rotation. The model was found to be suitable for engineering computations of rubber track systems internal resistance. From qualitative point of view, it successfully reproduced relationship between roller vertical load and rolling resistance coefficient at different roller tilt angles. In comparison with experimental results, vertical load at which one of roller's flanges lost contact with the track was also properly predicted. In exemplary computations, the model usually overestimated rolling resistance coefficient. However, estimation error did not exceed $16 \%$. Consequently, rolling resistance force was overestimated by no more than $10 \mathrm{~N}$. Such an error would not badly affect actual performance of a vehicle designed using the model.

\section{References}

Camso (2018) Conversion Track System. Brochure no. 1509_BrochureAG_CTS_EN_europeV6, available online: https://camso.co/content/files/products/AG/1507_BrochureCTS_EN_RGB_NA_170127_161920.pdf.

Dudziński, P., Chołodowski, J. (2016) Energy efficiency of rubber tracked chassis. Journal of KONES, vol. 23, no. 2, pp. 97-104.

Dudziński, P., Chołodowski, J. (2017) On internal resistance of rubber track systems. in: Proc. of the 19th International \& 14th European-African Regional Conf. of the ISTVS (eds. Kiss, P., Mathe, L. and Farkas, C.), ISTVS, Budapest, pp. 1-14.

Dudziński, P., Chołodowski, J., Ketting, M. (2018) Experimental tests on rolling resistance of road wheels in rubber tracked undercarriages. Article submitted to the 24th International Conference Engineering Mechanics 2018, Svratka, Czech Republic.

Rosenboom, L. (2008) Track assembly with idler wheels and cart incorporating same. US Patent no. 7.380.892.

Roth, T.A. (2004) Double-axis oscillating bogie wheels. US Patent no. US 6.712.549. 